\title{
1994 Year in Review: selected topics in respiratory medicine
}

Critical appraisals of advances, new ideas, or new diseases in respiratory medicine have always proved popular. Conference halls have always been full when clinical reviews are proffered by authorities in their field.

With this month's edition of Thorax the first of a series of selected topics from the previous year appear. The three editors - David Hendrick, Charles Hind, and Neil Pride - were asked to each choose four areas in which, in their opinion, an important manuscript or manuscripts were published in a peer reviewed medical journal. They then forwarded these manuscripts to experts within those fields and requested a review of that subject, looking at the pros and cons of the published paper and how it might affect clinical progress or research. The abstracts of those selected manuscripts appear at the head of each article and 12 such articles are contained within the first supplement.

Clearly, a single supplement cannot encompass all the innovations within a calendar year, and the areas chosen were, to some extent, the personal choice of the three supplement editors. Different topics will, of course, be covered in subsequent years, and it is hoped that this series will provide informative summaries as well as critical analyses of important developments in the field of respiratory medicine.

We all hope that the readers of Thorax enjoy this supplement and that it will prove a useful source of information this year.

STEPHEN G SPIRO 